\title{
Juicios paralelos y Constitución: su relación con el Periodismo
}

\author{
Abraham Barrero Ortega \\ Departamento de Derecho Constitucional \\ Universidad de Sevilla
}

\begin{abstract}
RESUMEN
“Cuando la prensa hace de juez".

Los medios de comunicación desempeñan funciones de vital importancia en el Estado democrático contemporáneo. Una de las más trascendentes es la de velar por la legitimidad democrática del Poder Judicial o, lo que es lo mismo, controlar que las decisiones judiciales se ajusten a la ley. Lo que ocurre es que, al informar sobre asuntos sub iudice, los medios pueden inducir en la opinión pública un veredicto anticipado de culpabilidad de una persona, con grave menoscabo de sus derechos fundamentales a la defensa, al honor y a la presunción de inocencia. De otro lado, a nadie se le oculta la negativa influencia que el juicio paralelo puede ejercer sobre la investigación judicial en curso y sobre la independencia e imparcialidad de los jueces profesionales o de los jurados.

El presente artículo analiza las posibilidades que ofrece nuestro ordenamiento jurídico en orden a la solución de estos conflictos entre la libertad de información y las reglas de funcionamiento de la administración de justicia, prestando una especial atención a los mecanismos de autocontrol ensayados por los profesionales de la información.
\end{abstract}

\section{ABSTRACT}

"When media act as a judge"

Media play an essential role in the contemporary democratic state. One of their most important functions is that which consists on surveying the democratic legitimacy of judiciary. They are instruments of popular control over judicial decisions. However, while media are reporting "sub iudice" matters they might be persuading people to believe in the guilt of a person before being condemned. As a result, they might be violating rights such as presumption of innocence, defence and honour. Furthermore, a parallel or simultaneous judgement in the media might exercise a negative influence on the trial and injure the independence and impartiality of the judges and the jury. Finally, sometimes they might interfere in the judicial investigation.

This article analyses the solutions that have been tried in our country and others in order to solve these conflicts between freedom of the press and the rules of judiciary. Needless to say, journalists have also formulated ethical rules and self-control private mechanisms to achieve this item.

Palabras claves: Juicio paralelo/Libertad de información/Independencia e imparcialidad judicial/Mecanismos de autocontrol o autorregulación/Juicio justo/Veracidad/Reportaje neutral

Key Words: Parallel or simultaneous judgement in the media/Freedom of the press/Independence and impartiality of the judges/Self-control private mechanisms/Fair Trial/Veracity/(News coverage). 


\section{Introducción}

T a Constitución española de 1978, tras reconocer el derecho de todos a un proceso con todas las garantías (art. 24.2), establece el principio de publicidad de los procesos (art. 120.1). Se trata de que terceras personas (el público) tengan la posibilidad de presenciar las actuaciones procesales, con las excepciones que prevean las leyes de procedimiento para salvaguardar los intereses de las partes o los fines del proceso.

La publicidad de las actuaciones procesales es una conquista del pensamiento ilustrado. Frente a la "justicia de gabinete" del Antiguo Régimen, el movimiento liberal apostó por la publicidad del procedimiento como garantía de los derechos naturales, inalienables y sagrados del hombre frente al arbitrio judicial y eventuales manipulaciones gubernamentales en la constitución y funcionamiento de los tribunales, así como medio para el fortalecimiento de la confianza del pueblo en la administración de justicia en tanto instrumento de control popular sobre la misma ${ }^{1}$. Como consecuencia de estos postulados ideológicos, el derecho a ser juzgado mediante un proceso público y ante un tribunal imparcial pasó a incluirse en la parte dogmática de los textos fundacionales del constitucionalismo ${ }^{2}$. El ciudadano ha de estar informado del funcionamiento de la justicia porque sus derechos fundamentales y la legitimidad democrática del poder judicial así lo exigen.

Dicho esto, a nadie se le oculta que los medios de comunicación juegan hoy un papel fundamental en la realización de este principio constitucional. Como han reconocido tanto el Tribunal Europeo de Derechos Humanos como nuestro Tribunal Constitucional, "el principio de publicidad de los juicios (...) implica que éstos sean conocidos más allá del círculo de los presentes en los mismos, pudiendo tener una proyección general" ${ }^{3}$. Y esta proyección no puede hacerse efectiva "más que con la asistencia de medios de comunicación social, en cuanto que tal presencia permite adquirir la información en su misma fuente y transmitirla a cuantos, por una serie de imperativos de espacio, tiempo, distancia, quehacer, etc., están en la imposibilidad de hacerlo"4.

Sin embargo, en ocasiones, al informar sobre asuntos sub iudice, se sustituye la jurisdicción estatal por el juicio mediático. En este sentido, hablamos de

1 Sobre ello López Ortega, J. J., "La dimensión constitucional del principio de publicidad de la justicia", Revista del Poder Judicial, XVII (Número especial/Justicia, Información y Opinión Pública), Consejo General del Poder Judicial, Madrid 1986, pp. 39-58.

2 Vid., entre nosotros, el artículo 302 de la Constitución gaditana de 1812, en Rico Linage, R., Constituciones históricas, Servicio de Publicaciones de la Universidad de Sevilla, Sevilla 1989, p. 57.

3 STC 30/1982, de 1 de junio. Por lo que se refiere a la jurisprudencia del Tribunal Europeo de Derechos Humanos, véase la sentencia Weber c. Suiza, de 22 de mayo de 1990.

4 Ibíd. En el mismo sentido, las sstc 13/1985, de 31 de enero, 128/1988, de 27 de junio, y 176/1988, de 4 de octubre. 
juicios paralelos cuando los medios de comunicación asumen un papel que está asignado constitucionalmente a los jueces y magistrados que integran el Poder Judicial del Estado (art. 117.3 CE). No hay juicio paralelo cuando la investigación periodística descubre asuntos y situaciones ilegales que acaban posteriormente en los tribunales, pues en tales casos los medios de comunicación cumplen su función constitucional. Pero una vez iniciadas las actuaciones judiciales, la frontera hasta donde debe llegar la información se hace menos nítida.

En verdad, el juicio paralelo en los medios puede alcanzar diversas intensidades. En su máxima expresión se llega a buscar testigos y pruebas a fin de confrontar las declaraciones de acusados, acusadores y peritos, lo que plantea problemas de relevancia constitucional. Uno de los más trascendentes es la vulneración de los derechos al honor, a la presunción de inocencia y a la defensa, pues se puede inducir en la opinión pública un veredicto anticipado de culpabilidad de una persona sin que ésta pueda disfrutar de las garantías que recoge la Constitución. Otro grave problema es la posible influencia de estos juicios paralelos sobre la imparcialidad de los jueces profesionales o la de los ciudadanos que forman un jurado. Sin olvidar la perturbación que la información de tribunales puede causar en el desarrollo de la investigación judicial.

Se plantea con ello un conflicto entre las reglas de funcionamiento de la administración de justicia y la libertad de información, que ha de resolverse conciliando la función constitucional de la justicia con la de los medios de comunicación. Resulta imprescindible evitar la sustitución de los jueces por la prensa, pero ello no debe ser una excusa para limitar el derecho de crítica pública a la justicia ${ }^{5}$ ni, por supuesto, limitar la publicidad de las actuaciones judiciales que consagra nuestro texto constitucional. Hay que conciliar la libertad de información con otros derechos, bienes y valores del mayor respeto y dignidad.

A falta de un precepto concreto que regule o limite la actuación de los medios de comunicación, la solución pasa necesariamente por el principio de proporcionalidad $^{6}$, ya que no cabe suprimir indiscriminadamente la información de tribunales, ni tampoco admitir, en virtud de una deficiente comprensión de la libertad de información, una publicidad incontrolada que atente contra derechos fundamentales, la imparcialidad de la justicia y las garantías del fair trial. Es doctrina constitucional que los derechos fundamentales, como todos los derechos subjetivos, no son derechos que puedan ejercitarse sin límite ninguno. Su ejercicio está sujeto a límites más allá de los cuales resulta ilegítimo. El Tribunal Consti-

5 Gimeno Sendra, V., "La sumisión del juez a la crítica pública”, Revista del Poder Judicial, cit., pp. 295306.

6 Sobre la significación jurídico-constitucional del principio de proporcionalidad, MEdina GuERRERo, M., La vinculación negativa del legislador a los derechos fundamentales, McGraw-Hill, Madrid 1996, pp. $117-$ 145 . 
tucional ha llegado incluso a reconocer la existencia de límites al ejercicio de los derechos que, aunque no se encuentran previstos de manera expresa, vienen impuestos por la propia lógica de nuestro sistema constitucional. Ahora bien, no cualquier bien o principio jurídicamente protegible puede actuar como límite de los derechos fundamentales. Si así fuera, resultaría sencillo vaciar de contenido tales derechos mediante la invocación de esos supuestos principios o bienes. Los límites implícitos a los derechos fundamentales, esto es, los no contemplados de manera expresa, han de basarse siempre en bienes constitucionalmente protegidos $^{7}$. En todo caso, no hay que olvidar que tanto en la determinación de cuáles son los posibles fundamentos de los límites a los derechos fundamentales como en la ponderación entre los límites constitucionalmente posibles y los propios derechos ha de tenerse muy presente "la fuerza expansiva de los derechos fundamentales, interpretando, pues, restrictivamente sus límites, que (...) deben resultar proporcionales de cara a obtener el fin que persiguen"».

\section{Juicios paralelos e interés de la justicia}

La constitucionalidad del artículo 301 de la Ley de Enjuiciamiento Criminal (LECrim), que recoge, como excepción a la regla general de publicidad del proceso penal, la existencia de una fase del mismo, la instrucción del sumario, en la que impera el secreto, ha sido reconocida por nuestro Tribunal Constitucional en sus sentencias 13/1985 y 176/1988.

El fundamento de esta excepción al principio de publicidad del proceso lo sitúa la última de las sentencias mencionadas en la "necesidad de asegurar la investigación de la verdad de los hechos, exigidas por el interés de la justicia penal", de modo que se eviten "interferencias y manipulaciones dirigidas a obstaculizar la investigación, en su objetivo de averiguar la verdad de los hechos". Así pues, según el Tribunal Constitucional, la razón última del secreto sumarial no radica en la conveniencia de salvaguardar la imparcialidad del juzgador, evitando presiones e influencias externas de los medios de comunicación y de la opinión pública, sino en la necesidad de garantizar la propia investigación judicial de la que depende el éxito de la justicia penal. El secreto del sumario es una medida práctica para garantizar la investigación, a los efectos, como dice la Exposición de Motivos de la LECrim, de "impedir que desaparezcan las huellas del delito y para recoger o inventariar los datos que basten para comprobar su existencia y reunir los elementos que más tarde han de utilizarse y depurarse en el crisol de la contradicción durante los solemnes debates del juicio oral y público".

7 Véase, por todas, la sTc 120/1990, de 27 de junio.

8 STC 158/1986, de 11 de diciembre. 
Por su parte, el Tribunal Supremo ha reafirmado este fundamento, pero ha hecho hincapié además en otro no apreciado por el Tribunal Constitucional, cual es la garantía del derecho al honor del imputado. En alguna ocasión, tras considerar intromisión ilegítima en el ámbito de este derecho "la divulgación de expresiones o hechos concernientes a una persona cuando la difame o la haga desmerecer en la consideración ajena", el Alto Tribunal ha aplicado esta categoría a la información que revelaba indebidamente datos de una querella presentada, concluyendo que "esta misma tipología viene agravada en los supuestos de actuaciones criminales dadas a conocer al público por vía de información periodística, olvidando el secreto de las diligencias sumariales conforme previene el artículo 301 de la Ley de Enjuiciamiento"10.

Así las cosas, cabría preguntarse si la difusión del contenido de las diligencias del sumario, que son secretas para el exterior (301 LECrim), es una conducta sancionable a tenor de lo dispuesto en el art. 197.3 del vigente Código Penal (CP 1995) ${ }^{11}$. Pues bien, la respuesta ha de ser negativa atendiendo a la doctrina jurisprudencial que considera que este precepto contiene una regulación genérica que cede ante la regulación específica de la violación del secreto del sumario contenida en el artículo $466 \mathrm{CP}^{12}$.

Pero es que, además, con arreglo a la interpretación que nuestro Tribunal Constitucional ha realizado de los preceptos que regulan el secreto del sumario, si lo que se difunde es una declaración de una persona, sea o no testigo o imputado, no sobre el resultado de las diligencias, sino sobre los hechos o circunstancias que él presenció o en los que directa o indirectamente tomó parte, o con los que tuvo relación de algún tipo o simplemente conoció por referencia de otras personas, no estaremos ante una conducta sancionable. Para el Tribunal Constitucional, lo que persigue el secreto del sumario es impedir a todos, incluidas las partes en algunos casos (art. 302 LECrim), acceder a las actuaciones judiciales en esa fase procesal, pero no prohíbe conocer por medios lícitos y al margen de la actuación judicial cualquier hecho referente a la materia que se discute. El secreto del sumario se predica sólo de las diligencias que lo constituyen, pero no significa, en modo alguno, "que uno o varios elementos de la realidad social sean arrebatados a la libertad de información"13. De ser así, el mal entendido secreto del sumario

$9 \quad$ STS de 19 de octubre de 1995.

10 Ibíd.

11 El artículo 197.3 CP sanciona la difusión, revelación o cesión de los datos reservados a terceros. Consta de dos apartados muy claramente diferenciados. En el primero se contempla un tipo cualificado para quienes, además de realizar la conducta de apoderamiento de un secreto, lo divulgan a terceros. En el segundo, se describe un tipo atenuado para aquellos cuya conducta consista únicamente en difundir, revelar o ceder, no habiendo participado en el previo descubrimiento de los secretos ajenos.

12 El artículo 466 CP sanciona la revelación de actuaciones judiciales secretas. En este caso, la conducta típica estriba en revelar actuaciones procesales declaradas secretas por la autoridad judicial.

13 STC 13/1985, de 31 de enero. 
"equivaldría a crear una atípica e ilegítima materia reservada sobre los hechos mismos acerca de los cuales investiga y realiza la oportuna instrucción el órgano judicial, y no sobre las actuaciones del órgano judicial que constituyen el sumario" ${ }^{14}$. Es decir, quedan cubiertos por el secreto del sumario los conocimientos extraídos de las propias actuaciones judiciales, pero no lo sabido al margen del proceso, no las informaciones obtenidas antes o fuera del proceso, lo que significa, no sólo que los terceros que tengan conocimiento de algunos hechos relacionados con la investigación judicial puedan relatarlos públicamente, sino que los propios testigos y el imputado pueden descubrir públicamente lo que hayan declarado ante el juez instructor, pues el conocimiento de tales datos no procede del sumario, sino de la percepción directa o indirecta de los hechos.

De nuevo la pregunta se impone. Con esta interpretación estricta del secreto del sumario que realiza el Tribunal Constitucional, ¿dónde queda la garantía de la investigación? ¿y dónde la garantía del derecho al honor del imputado?

Se diría que el Tribunal contradice su propia doctrina sobre el fundamento del secreto sumarial, ya que, en la práctica, lo deja reducido casi a la nada, convirtiendo en inoperante, en un recipiente vacío de contenido, la institución. Si cualquier persona que tenga un conocimiento mediato o inmediato de los hechos puede confiar a un periodista cualquier extremo relacionado con la investigación judicial, lo haya o no revelado ante el juez en el curso de las diligencias sumariales, es evidente que las garantías para que no desaparezcan las huellas del delito, no se condicione el juicio o las contestaciones de testigos, o no se manipulen los elementos que han de utilizarse y cribarse durante los debates del juicio público, quedan en jaque. Y lo mismo ocurre con las garantías del derecho al honor del imputado.

Éstos son sólo algunos de los problemas que se derivan de una tesis del Tribunal Constitucional que, en mi opinión, no resulta del todo satisfactoria: la que propugna que la realidad investigada por el juez no se sustrae a la libertad de información siempre que el conocimiento obtenido y, en su caso, publicado no proceda de las propias actuaciones procesales. Una tesis discutible porque, como digo, conduce a resultados incompatibles con la función constitucional del secreto del sumario.

Una posible vía para salir de esta encrucijada pasaría por interpretar, en contra de la doctrina emanada de la STC 13/1985, el secreto sumarial del artículo 301 LECrim en el sentido de entender incluido en el deber de reserva tanto el resultado de las actuaciones procesales como el contenido de la investigación. Desde esta perspectiva, se aboga por un cambio de la doctrina constitucional en el sentido enunciado y por una regulación legal, eso sí, todo lo precisa y ponderada 
que se quiera, para garantizar eficazmente la acción de la justicia y el derecho al honor del imputado mediante un efectivo secreto externo (frente a terceros) de la fase sumarial. Se insta, en suma, a una adecuada distinción entre publicidad y publicabilidad, ya que, como la práctica demuestra, no basta con que la ley o el juez declaren secretas las actuaciones sumariales, esto es, eliminen su carácter público, sino que es necesario que prohíban su publicación.

Así ocurre, por ejemplo, en Italia, donde el apartado 1 del artículo 114 del Código de Procedimiento Penal excluye terminantemente la publicación (incluso la parcial o resumida) del contenido de los actos cubiertos por el secreto durante la fase de indagini preliminari. No obstante, y como excepciones a la regla, los apartados 2 y 3 del artículo 329 del Código conceden al ministerio público amplias facultades para levantar esa prohibición en atención a las circunstancias de cada caso, con lo que en la práctica se estructura una regulación flexible que permite alcanzar soluciones proporcionadas ${ }^{15}$. También en Portugal los medios de comunicación social son objeto de una referencia específica en el artículo 86 del Código de Procedimiento Penal, que sólo permite la publicación de "narraciones circunstanciadas" de los actos procesales no sometidos a secreto. En realidad, salvo puntuales excepciones previstas en la ley, en el ordenamiento jurídico portugués el régimen del secreto coincide con el de la publicidad de los actos y documentos del proceso, quedando así vedada no sólo la posibilidad de que los profesionales de la información realicen investigaciones paralelas durante el desarrollo de la inquérito y la instruçao, sino también la publicación de comentarios subjetivos o la utilización de cualquier género periodístico distinto al reportaje neutral ${ }^{16}$.

En Alemania y Francia, por el contrario, la doctrina científica echa en falta una regulación precisa de estos aspectos. Ni la Ordenanza Procesal alemana ni el Código de Procedimiento francés se refieren al acceso de los medios de comunicación a los datos de la investigación judicial. Sólo existen en estos dos países algunas disposiciones que penalizan la violación del secreto durante la fase de instrucción, sin que tales normas afecten a los medios de comunicación cuando informan lato sensu de la investigación judicial en curso. La conclusión a la que en uno y otro caso se ha llegado es que el problema de la actividad de los medios de comunicación en relación con la acción de la justicia es un problema real que difícilmente puede solventarse a partir de una regulación tan insuficiente ${ }^{17}$.

15 Rodríguez Bahamonde, R., El secreto del sumario y la libertad de información en el proceso penal, Dykinson, Madrid 1999, pp. 45-57.

16 Ibíd, pp. 66-75.

17 Ibíd., pp. 41-45 y 57-66. Sobre el caso francés, véase también Dupeux, J. I. y Lacabarats, A. (dirs.), Liberté de la presse et droits de la personne, Dalloz, París 1997, pp. 95-149. 
Por otra parte, sorprende que en nuestro propio ordenamiento, para favorecer la investigación, la ley prevea la posible incomunicación del detenido ${ }^{18}$, medida que entraña una radical privación de sus derechos fundamentales, e incluso la posibilidad de que, por decisión judicial, las actuaciones sumariales sean secretas para las partes $^{19}$, y no pueda imponer la efectividad frente a terceros del secreto del sumario mediante la prohibición de publicación de su contenido. Ningún obstáculo habría para ello. No lo hay desde la perspectiva del ordenamiento jurídico interno, pues, como el propio Tribunal Constitucional puntualizara en la sentencia 176/1988, el derecho constitucional a un proceso público se refiere sólo a la fase de oralidad, por lo que el secreto del sumario, incluso en su máxima expresión, "en nada afecta al derecho a un proceso público", extendiéndose además este secreto, según se afirma en la STC 13/1985, no sólo al derecho a recibir información, sino también al de "difusión por cualquier medio", es decir, al derecho a dar información. Y tampoco lo hay desde el punto de vista de los Tratados y Convenios Internacionales suscritos por nuestro país. En efecto, según el artículo 6.1 del Convenio Europeo de Derechos Humanos de 1950, tal y como ha sido interpretado por el Tribunal Europeo de Derechos Humanos, la publicidad procesal sólo es exigible en la fase de juicio oral y en el pronunciamiento de la sentencia. Asimismo, el artículo 11 del Convenio, que garantiza las libertades de expresión e información, permite que su ejercicio se someta a ciertas restricciones y condicionamientos por la ley para la "protección de la reputación de los derechos ajenos, para impedir la divulgación de informaciones confidenciales o para garantizar la autoridad e imparcialidad del poder judicial"20.

La aplicación de estas consideraciones a nuestro proceso penal, en el que se distingue una fase preparatoria de instrucción y una posterior plenaria, que finaliza con el acto solemne del juicio oral y el posterior pronunciamiento de la sentencia, conduce a la conclusión de que el derecho al proceso público del art. 24.2 CE, como garantía del justiciable, sólo es de aplicación, además de a la sentencia, al proceso en sentido estricto, en el que se producen o reproducen las pruebas de cargo y descargo y se formulan las alegaciones y peticiones definitivas de la acusación y la defensa, pues únicamente referida a ese acto procesal tiene sentido la publicidad del proceso en su verdadero significado de participación y de control de la justicia por la comunidad. Dicho de otro modo, desde su dimensión de garantía de los justiciables contra una justicia secreta que escape a la fiscalización

18 Arts. 506 y ss. LECrim.

19 Art. 302 LECrim.

20 Sobre esta cuestión, Pettiti, L. E. (dir.), La Convention Européenne des droits de l'homme: commentaire article par article, Economica, París 1995; BonEt, J., El derecho a la información en el Convenio Europeo de los Derechos Humanos, PPU, Barcelona 1994, pp. 205 y ss.; Tiтium, P., "Libertad de información y Poder Judicial en el Convenio Europeo de Derechos Humanos", Revista del Poder Judicial, cit., pp. 361370 . 
del público, el principio de publicidad no es aplicable a todas las fases del proceso penal, sino tan sólo al acto oral que lo culmina y al pronunciamiento del subsiguiente fallo.

\section{Juicios paralelos y presunción de inocencia en la opinión pública}

El derecho a la presunción de inocencia del artículo 24.2 de la Constitución se proyecta específicamente sobre los procesos en los que se ventilan sanciones penales o administrativas. Se ha discutido, no obstante, si la presunción de inocencia, como derecho fundamental, es ejercitable solamente frente al Estado, es decir, como prerrogativa del justiciable frente a los tribunales en cualquier proceso penal o frente a la Administración en cualquier procedimiento sancionador, o también es ejercitable frente a los particulares. Nuestro Tribunal Constitucional, desde la sentencia 166/1995, ha optado por esta segunda tesis, afirmando que la presunción de inocencia es ejercitable frente al Estado, ex artículo 24.2 CE, y frente a los particulares, como una cualidad integrante del honor, ex artículo $18 \mathrm{CE}$.

La presunción de inocencia es un derecho de la persona frente al Estado e impide, como expresa la citada sentencia, un pronunciamiento de condena "que no esté fundado en pruebas que, legítimamente obtenidas, se hayan practicado con todas las garantías legalmente exigidas", extendiéndose la necesidad de esas pruebas "a todos los elementos objetivos del delito y a los elementos subjetivos del tipo en cuanto sean determinantes de la culpabilidad". Derecho que se concreta en una presunción iuris tantum, en virtud de la cual toda acusación debe ir acompañada de la prueba de los hechos en que consiste, de tal manera que, si no concurren tales pruebas, el juez o tribunal que conozca el proceso deberá declarar la inocencia del acusado. No se trata de una garantía nueva en nuestro ordenamiento jurídico, pues tradicional y básico en nuestro Derecho penal es el principio in dubio pro reo, esto es, en caso de duda hay que inclinarse por la interpretación más favorable al reo, y también es clásica la exigencia de que la acusación ha de probar los hechos en que se funda. Lo que sí constituye una novedad es la constitucionalización de tales principios como un derecho fundamental del acusado, de forma que éste, en caso de su infracción, podrá acudir ante los tribunales ordinarios y, en última instancia, ante el Tribunal Constitucional para recabar su tutela.

Pero, como se ha dicho, no es cierto que la presunción de inocencia sea sólo un derecho público subjetivo ejercitable frente al Estado. La STC 166/1995 reconoce la dimensión extraprocesal de esta garantía:

“(...) la presunción de inocencia tiene también una dimensión extraprocesal y comprende el derecho a recibir la consideración y el trato de no autor o partícipe en hechos de carácter delictivo o análogos a éstos y determina, por ende, el derecho a que no se apliquen las consecuencias o los efectos 
jurídicos anudados a hechos de tal naturaleza en las relaciones jurídicas de todo tipo. Pero esta dimensión extraprocesal de la presunción de inocencia no constituye, por sí misma, un derecho fundamental distinto y autónomo del que emana de los artículos 10 y 18 de la Constitución, de tal modo que ha de ser la vulneración de este precepto y, señaladamente del artículo 18, lo que sirve de base a su protección a través del recurso de amparo".

Se amplía así lo que pudiera denominarse el radio de acción de la presunción de inocencia, que pasa a concebirse como una técnica de protección de la dignidad de la persona frente a toda clase de imputación no probada. En otras palabras: una vez consagrada constitucionalmente, la presunción de inocencia ha dejado de ser un principio general del derecho que ha de informar la actividad judicial (in dubio pro reo) para convertirse en un derecho fundamental que vincula no sólo a los poderes públicos sino también a algunos poderes privados (p.e. el denominado poder mediático) $)^{21}$, y que es de aplicación inmediata.

Ahora bien, ¿alguien cree de verdad que es posible hacer respetar esa presunción y esa consideración de no autor o no partícipe en los hechos imputados cuando una publicación sistemáticamente parcial del contenido del proceso conforma una opinión pública contraria?

De entre los ordenamientos jurídicos de nuestro entorno, el francés ha sido el primero en reaccionar ante esta grave situación. Allí, una exhaustiva y recentísima ley, la Ley 2000-516 de 15 de junio de 2000, de protección de la presunción de inocencia y de los derechos de las víctimas, ofrece las siguientes soluciones:

a) El órgano judicial podrá ordenar la publicación de un escrito de rectificación cuando una persona sea presentada públicamente como culpable de unos hechos sobre los que hay abierta una investigación ${ }^{22}$.

b) La ley sanciona con una multa de 100.000 francos a quien, sin autorización, publique por cualquier medio la imagen de una persona implicada en un procedimiento penal o difunda un sondeo de opinión acerca de su culpabilidad ${ }^{23}$.

c) Las autoridades habrán de adoptar las medidas más eficaces y compatibles con las exigencias de la seguridad para evitar que una persona esposada sea fotografiada u objeto de un reportaje audiovisual ${ }^{24}$.

d) En todo caso, y a fin de contestar informaciones parciales o inexactas, el ministerio fiscal, en el ejercicio de su función de garante de los derechos de los ciudadanos, podrá, de oficio o a instancia de parte, divulgar datos objetivos de la

21 Bilbao Ubillos, J. M., La eficacia de los derechos fundamentales frente a particulares, Centro de Estudios Constitucionales, Madrid 1997, pp. 241-256.

22 Artículo 91.

23 Artículo 92.

24 Artículo 93. 
investigación judicial, sin que ello suponga prejuzgar la culpabilidad o inocencia del imputado ${ }^{25}$.

Por lo que al ordenamiento español se refiere, en ausencia de una regulación precisa como la francesa, cabría potenciar la aplicación, con una interpretación jurisprudencial que la haga eficaz, de la doctrina contenida en la STC 219/1992, donde se declara que "la exigencia de una información veraz obliga a respetar el derecho de todos a la presunción inocencia, reconocido en el artículo 24.2 CE", y que "el único acto que puede quebrar la presunción de inocencia del acusado es la sentencia del Tribunal que declara la autoría del delito". Y es que de algún modo hay que reaccionar frente a la información que, desconociendo el significado de la presunción de inocencia, da por cierta la culpabilidad de una persona por el mero hecho de verse sujeta a una investigación judicial.

Ésta es, por otra parte, la tesis que parece aceptar la STC 6/1996, aunque referida al período de diligencias judiciales previas. En ella, después de concluir que "se podía haber informado a la opinión pública lisa y llanamente de la investigación en curso", el Tribunal Constitucional desestimó el recurso de amparo interpuesto por unos periodistas frente a unas resoluciones judiciales que le condenaban al pago de una indemnización por intromisión ilegítima en el derecho al honor. Los periodistas imputaban a una persona determinada e identificada por su nombre, apellidos y fotografía, la intervención directa como intermediario en un secuestro, lo que, a juicio de los tribunales de instancia, no se acompañaba de prueba alguna que pudiera acreditar la veracidad de la información. Aunque se dijera que la noticia se había contrastado, lo cierto era que en la información sólo se citaban fuentes indeterminadas, olvidando que corresponde a quien la ofrece probar la veracidad de lo que difunde. Por el contrario, en la demanda de amparo se alegaba que la información ofrecida en el artículo respondía al canon de veracidad que el texto constitucional impone. La información fue debidamente contrastada con diversas fuentes (entrevistas con testigos, con las Fuerzas de Seguridad del Estado y con fuentes cercanas a la organización terrorista), quedando así satisfecho el deber de diligencia que incumbe al informador en relación con la exigencia constitucional de veracidad en la comunicación.

Por su parte, el Tribunal Constitucional comienza su argumentación insistiendo en que el contenido del art. 20.1 d) CE no es otro que la información veraz. A este respecto matiza que la veracidad de la información no es sinónimo de la verdad objetiva e incontestable de los hechos, sino reflejo de la necesaria diligencia en la búsqueda de lo cierto. De este modo, la veracidad de lo que se informa no va dirigida a la exigencia de una rigurosa y total exactitud del contenido de la información, sino a negar la protección constitucional a los que, defraudando el

25 Artículo 96. 
derecho de todos a recibir información veraz, transmiten como hechos verdaderos bien simples rumores, carentes de toda constatación, bien meras invenciones o insinuaciones, sin desplegar la diligencia exigible a un buen profesional.

La aplicación de esta doctrina al caso concreto impidió al Tribunal Constitucional reconocer que el artículo periodístico constituyera una manifestación constitucionalmente protegida del derecho a la libertad de información veraz alegado por los recurrentes. Ciertamente la noticia no arrancaba del vacío, sino de la existencia de una actuación policial y judicial previa sobre la persona objeto de la información que, en cierto modo, reclamó el interés de los periodistas, por lo que, aunque tales actuaciones fueron definitivamente archivadas, lo difundido no fue producto de una invención deliberada. Ahora bien, el Tribunal rechaza a renglón seguido que la información suministrada pudiera encuadrarse dentro de la categoría del reportaje neutral, pues el medio de comunicación no se limitó a desvelar la existencia de una investigación en curso o a reproducir declaraciones de otras personas suficientemente identificadas. Los periodistas hicieron suya una versión de los hechos, la inculpatoria, anticipando así peligrosas y graves conclusiones, lo que implicó una intromisión ilegítima en el derecho al honor del presunto intermediario porque carecían de todo apoyo real, sin que los autores del reportaje hubiesen probado lo contrario. El artículo periodístico no fue el resultado de una diligente investigación periodística.

Pues bien, trasladando los resultados de este pronunciamiento a otros supuestos similares, se podría establecer como regla general que la veracidad exigible a la publicación de noticias sobre el proceso no se satisface con la simple comprobación de que las noticias difundidas se corresponden con lo alegado o declarado por una de las partes (acusador, Fiscal o testigos de la acusación) como entiende la tesis del reportaje neutral. Y ello porque se sabe, al publicarlas, que esas alegaciones o declaraciones son controvertidas y pueden no resultar verdaderas o exactas. Pueden no ser estimadas en la sentencia. El informador es perfectamente consciente de que durante el proceso aún no se conoce la verdad, la oficial claro está, aunque se está en vías de conocerla. Y conociendo que la verdad durante el proceso es una verdad discursiva o controvertida ${ }^{26}$, no ha de alinearse con la parte acusadora. Su noticia tendrá que aludir a los dos caras de la verdad, esto es, a la que surge de la confrontación de imputaciones, declaraciones y alegaciones de las dos partes (acusación y defensa). Por ello, la publicación sistemática de una sola de las caras, precisamente la peor para el imputado, no puede considerarse como una información que cumpla con el requisito de la

26 Carnelutti, F., Derecho Procesal Civil y Penal, v. II, Ediciones Jurídicas Europa-América, Buenos Aires 1971, pp. 229-236. 
veracidad. Esta debería ser la "actuación razonable" ${ }^{27}$ exigida al periodista por el Tribunal Constitucional.

\section{Juicios paralelos e imparcialidad judicial}

El artículo 24.2 CE reconoce a todos el derecho a un juicio público con todas las garantías, entre las que debe incluirse, aunque no se cite de forma expresa, el derecho a un juez imparcial, que constituye sin duda una garantía fundamental de la Administración de Justicia en un Estado de Derecho, como es el nuestro de acuerdo con el artículo 1.1 de la Constitución ${ }^{28}$.

Pero si uno de los derechos más fundamentales del justiciable es ser juzgado por un tribunal imparcial e independiente hay que reconocer que esa imparcialidad e independencia pueden verse en algunos casos enturbiadas por campañas mediáticas, orientadas unas veces a defender determinadas posturas de los medios y otras simplemente a defender un interés empresarial a través de la publicación de noticias especialmente atractivas para el público. Adviértase como la publicidad del proceso, que es recogida constitucionalmente como una garantía democrática para el procesado y para la acusación, en cuanto procura la máxima justicia al evitar las corruptelas que podrían ampararse en el secreto de las actuaciones, puede convertirse en uno de los enemigos más terribles de la justicia democrática, en cuanto unos poderes privados, los que dominan los medios de comunicación, pueden estorbar la obtención de esa máxima justicia al perturbar la objetividad de jueces y tribunales.

En realidad, el juez ni es ni puede ser una persona encerrada en un marco estricto de preceptos jurídicos y aislada del clima social que le rodea. Es la ley misma la que, en determinados supuestos, le pide que tenga en cuenta ese clima social para modular su aplicación. Así, por ejemplo, el art. 503 LECrim contempla la alarma social producida por la comisión de un delito como uno de los criterios que ha de valorar el órgano jurisdiccional para decretar o no la prisión provisional. Pero si el juez no debe ni puede ser un Robinson Crusoe, sí ha de estar, de alguna forma, amparado frente a la opinión pública para que ésta no limite su independencia o, lo que es lo mismo, su sometimiento exclusivo a la Constitución y al resto del ordenamiento. Aquí descansa precisamente la legitimidad democrática del juez constitucional. La propia Constitución exige que los titulares de la potestad jurisdiccional sean jueces y magistrados "independientes, inamovibles, responsables y sometidos únicamente al imperio de la ley" (art. 117.1). En idéntico sentido se pronuncian los artículos 14.1 del Pacto Internacional de Derechos Civiles y Políticos y 6.1 del Convenio Europeo de Derechos Humanos cuando

27 Sobre esta noción, Pérez Royo, J., Curso de Derecho Constitucional, Marcial Pons, Madrid 1999, pp. 431433.

28 Ibíd., pp. 871-876. 
reconocen el derecho de todos a ser juzgados por un "tribunal independiente e imparcial".

Y si esto se predica para los jueces y magistrados profesionales, qué decir respecto a los efectos perniciosos que la presión de la opinión pública puede ejercer sobre los ciudadanos que integran un jurado. La preocupación por esta cuestión quedó plasmada en el informe del Consejo General del Poder Judicial sobre el Anteproyecto de Ley Orgánica del Tribunal del Jurado. En dicho informe se sugería la necesidad de contemplar algunas medidas preventivas y, entre ellas, la posibilidad de otorgar facultades al magistrado presidente para frenar la publicación de noticias sobre el proceso. Sin embargo, ninguna de las medidas sugeridas quedaron plasmadas en la Ley Orgánica de 22 de mayo de 1995.

En esta misma dirección, el artículo 6.1 del Convenio Europeo de Derechos Humanos justifica la restricción de la publicidad en la fase oral del proceso en los casos en que esa publicidad "pudiera ser perjudicial para los intereses de la justicia". Por su parte, la jurisprudencia del Tribunal Europeo de Derechos Humanos viene presidida en esta materia por la idea de que el ejercicio de la libertad de información ha de ser respetuosa tanto con la posición institucional de los tribunales de justicia en una sociedad democrática como con la necesidad de asegurar para éstos un funcionamiento imparcial e independiente. Ya en la sentencia Sunday Times c. Reino Unido de 26 de abril de 1979, tras reconocer la posición preponderante de la libertad de información y rechazar la oportunidad de una limitación, el Tribunal advirtió de los peligros que para la autoridad del Poder Judicial representaban los juicios paralelos, máxime "si el público se habitúa al espectáculo de un pseudoproceso en los medios de comunicación". Una advertencia que, andado el tiempo, le ha llevado a declarar ajustada al Convenio la posibilidad de que las legislaciones nacionales establezcan medidas restrictivas de la libertad de información destinadas a garantizar la imparcialidad de los jueces, pero siempre y cuando resulten necesarias y proporcionadas al caso concreto ${ }^{29}$. La libertad de información goza, pues, de un trato preferente cuando entra en conflicto con otros intereses públicos, pero la preferencia no significa imposición incondicional.

En nuestro país alguna doctrina, haciéndose eco de la realidad de estas presiones y de sus posibles efectos en jueces y tribunales, ha planteado la necesidad de establecer ciertos límites a la información sobre los procesos. Y es que, aun subrayando el alto significado y cometido de la libertad de información en una democracia, hay que admitir que esta libertad no es absoluta y puede encontrar límites que habrán de operar con más intensidad en las fases procesales que

29 Vid. las sstedh Prager y Oberschlik c. Austria, de 26 de abril de 1995, y Worm c. Austria, de 29 de agosto de 1997. 
preceden a la decisión judicial, precisamente para no enturbiar la serenidad que debe presidir su pronunciamiento. La realidad nos muestra, sin embargo, que, en el momento actual, nuestro legislador y nuestra jurisprudencia se mantienen de espaldas a ellos, contrarios, o cuanto menos indecisos, ante la menor posibilidad de poner trabas a la información de tribunales para tratar de conciliar las libertades de expresión e información con otros derechos del imputado o acusado ${ }^{30}$.

No ocurre lo mismo en otros ordenamientos europeos en los que, aunque sea con un ámbito muy restringido, existen algunas medidas que permiten condicionar la publicación de noticias sobre el proceso. La más clásica es el contempt of court del derecho anglosajón que permite la prohibición de la difusión de datos sobre un asunto pendiente de resolución judicial para no menoscabar la independencia o imparcialidad del juez o tribunal. En el Derecho Francés, el artículo 434-16 de su vigente Código Penal castiga la publicación de comentarios sobre un asunto $s u b$ iudice cuando se realiza con la finalidad de ejercer presiones sobre las declaraciones de los testigos o sobre la decisión del juez. Por último, también la legislación federal austríaca sobre los medios de comunicación, en su artículo 23, tipifica como delito la influencia abusiva sobre un procedimiento penal.

En los Estados Unidos, en cambio, es la jurisprudencia la que ha ido arbitrando soluciones. La sentencia Sheppard v. Maxwell (1966) incorpora el primer intento del Tribunal Supremo por encontrar el punto de equilibrio entre las exigencias del principio de publicidad y el derecho a un juicio justo. Pero, sin duda, el leading case de la jurisprudencia americana en la materia es el resuelto en la sentencia Nebraska Press Association v. Stuart (1976), en la que el Alto Tribunal declara la nulidad de un proceso al estimar que el juez no cumplió con su obligación de proteger al acusado frente a una campaña mediática contraria a sus intereses. El juez podría haber optado entre diversas medidas para garantizar el fair trial: restringir la difusión del abundante material extraprocesal, suspender el juicio hasta que la publicidad generada a su alrededor hubiera cesado o, al menos, se hubiera calmado, aislar al jurado, examinar e instruir a sus miembros para despejar cualquier duda acerca de su imparcialidad e, incluso, decretar el cambio de jurisdicción. Pero no fue asíi1.

Volviendo a la situación española, es claro que se debe mantener a ultranza y sin restricciones la publicidad del proceso en la fase oral, porque esa publicidad es efectivamente una garantía constitucional para la justicia, al procurar una máxima transparencia respecto a las actuaciones del proceso. Sin embargo, sería

30 Sobre las escasas posibilidades que en esta materia ofrece nuestro ordenamiento, FolgUERA CRESPO, J., "Sobre la intervención mediadora del Consejo General del Poder Judicial en supuestos de posible perturbación de la independencia judicial", Revista del Poder Judicial, cit., pp. 505-516.

31 Sobre ello Tribe, L. H., "Communication and Expression", en American Constitutional Law, Mineola, New York 1988, pp. 856-861. 
aconsejable poner coto a la presión mediática ejercida en un sólo sentido, en una sola dirección, a través de una adecuada regulación dirigida a evitar manipulaciones interesadas. Aun sin llegar tan lejos como en otros ordenamientos, cabría aquí exigir a la información de tribunales que valore las dos caras de la verdad propia de esta fase. La veracidad como límite interno de la libertad de información así lo exige, de modo que la actuación razonable exigible al periodista se concretase en ese deber de contraste. Sin perjuicio, claro está, de que lo que es pura opinión pueda expresarse en cualquier sentido, siempre que se haga abiertamente y no camuflada bajo la apariencia de una información.

\section{Juicios paralelos y autocontrol de los medios de comunicación}

Los profesionales de la información tampoco ignoran la trascendencia constitucional de estas tensiones. Buena prueba de ello es la proliferación de códigos éticos y la creación y autorregulación de mecanismos privados de autocontrol, encargados de velar por el respeto a los principios que deben inspirar la actividad de los medios y, en particular, la honestidad de las informaciones que se refieren al proceso ${ }^{32}$. Lo distintivo de la autorregulación es que tanto su puesta en marcha como su funcionamiento y efectividad dependen del compromiso voluntario de los tres sujetos implicados en el proceso de la comunicación: los propietarios y gestores de las empresas de comunicación, los profesionales y el público que recibe la información. La autorregulación implica, pues, un desplazamiento del ajuste normativo del funcionamiento de los medios desde el Estado a la sociedad civil. Precisamente por tratarse de una iniciativa de la sociedad civil que se concreta en una regulación deontológica y moral, la única capacidad coactiva de la autorregulación descansa en su eco en la opinión pública. Algo muy valioso porque demuestra la madurez de una sociedad cuyos miembros son capaces de asumir libremente responsabilidades y compromisos al margen de sus intereses particulares.

En esta línea, la Federación de Asociaciones de la Prensa de España, en Asamblea celebrada en noviembre de 1993, aprobó un Código Deontológico de la Profesión Periodística, en cuyo punto 5 se afirma que el periodista "debe asumir el principio de que toda persona es inocente mientras no se demuestre lo contrario y evitar al máximo las posibles consecuencias dañosas derivadas del cumplimiento de sus deberes informativos", especialmente "cuando la información verse sobre temas relacionados con los Tribunales de Justicia". Tras el Código Deontológico de 1993, la LV Asamblea de la Federación de Asociaciones de la Prensa de

32 Vid. Aznar, H., Ética y Periodismo. Códigos, Estatutos y otros documentos de autorregulación, Paidós, Barcelona 1999; De Carreras, L., "La autorregulación como alternativa a las restricciones legales informativas y como sistema de relación entre televisiones y los jueces", Revista del Poder Judicial, cit., pp. 251-271. 
España aprobó en mayo de 1996 la constitución de una Comisión de Autocontrol de Deontología periodística. Por otro lado, la Asamblea Parlamentaria del Consejo de Europa adoptó en julio de 1993 una propuesta de Código Europeo de Deontología del Periodismo, en cuyo punto 22 se dice que "las informaciones y opiniones deben respetar la presunción de inocencia, principalmente en los temas que permanecen sub iudice, excluyendo establecer juicios paralelos".

Pero quizá sea en el campo de la televisión donde más se esté avanzando en orden a la fijación de criterios de autocontrol y a la conclusión de acuerdos complementarios entre las empresas del sector. Como ejemplos recientes, el dictamen del Consejo de lo Audiovisual de Cataluña de 6 de octubre de 1997 y la propuesta de convenio de autorregulación de 1998 suscrita por los directores de Televisión Española, Canal Plus, CNN Plus, Canal Sur, Televisió de Catalunya, Euskal Telebista, Televisión de Galicia, Televisión Valenciana y Tele Madrid, sobre celebración de los juicios y su tratamiento televisivo. Ambas iniciativas coinciden en la apreciación de que la atención informativa generada por algunos procesos plantea nuevos requerimientos a la Administración de Justicia, tanto respecto a la transparencia de su actuación como a las garantías de independencia en el ejercicio de su función, y en la necesidad de precisar criterios que permitan dar operatividad a los principios de objetividad, veracidad e imparcialidad de las informaciones sobre esos procesos. Conscientes, en suma, de que la regla de la publicidad de las actuaciones judiciales no es ilimitada, formulan las siguientes recomendaciones:

a) La aprobación de una iniciativa legislativa destinada a clarificar los supuestos en los que sea legítimo sacrificar la información de tribunales, de acuerdo con lo dispuesto en los artículos 6.1 y 10.2 del Convenio Europeo de Derechos Humanos y el artículo 14.1 del Pacto Internacional de Derechos Civiles y Políticos. Entretanto, y mientras se desarrollan los debates del juicio oral, las televisiones deberían abstenerse de programar la intervención de aquellas personas que constituyan medios de prueba, en especial testigos y peritos.

b) La asunción por las instituciones públicas de una labor didáctica orientada a concienciar a los ciudadanos de que, pese a los errores de la Administración de Justicia, sólo a través del proceso se satisfacen las garantías específicas del imputado. Asimismo, sería aconsejable que los medios de comunicación prestasen su colaboración a esta causa, difundiendo la idea de que la verdad oficial es la que asume la sentencia firme. En particular, las cadenas habrían de advertir a los espectadores de los peligros que encierra dar por buena la reconstrucción ficticia en televisión de los hechos y elementos que se están depurando en los solemnes debates del juicio público.

c) El establecimiento de una colaboración leal entre la Administración de Justicia y los profesionales de la comunicación a través de la designación de un intermediario encargado de suministrar información técnica del desarrollo del 
proceso. Por su parte, los medios habrían de dar a las informaciones del portavoz un tratamiento de credibilidad, sin perjuicio, claro está, de la libertad de expresión de cada informador. Es decir, los medios, también en el seguimiento de un proceso, han de observar el principio deontológico de separación entre información y opinión. No hay que confundir los hechos con las interpretaciones que de esos hechos haga una de las partes del proceso. La información ha de ser plural, aludiendo de manera objetiva a las posiciones contradictorias de acusación y defensa.

d) Tratamiento especial de la información de tribunales que afecte a menores y adolescentes, al objeto de proteger su intimidad y el desarrollo de su personalidad. Convendría evitar principalmente la difusión del nombre, la voz, la imagen y demás datos que faciliten su identificación, salvo en los supuestos de que hubiesen sido víctimas de un asesinato u homicidio o lo aconseje el éxito de la investigación.

e) Determinadas personas que actúan como medio de prueba en un juicio no lo hacen voluntariamente, sino en virtud de una prescripción legal o de un mandato judicial, por lo que tienen derecho a salvaguardar su intimidad y su propia imagen. A tal efecto, las televisiones deberían abstenerse de difundir su imagen, salvo en caso de renuncia expresa a sus derechos.

f) En los juicios con jurado es necesario extremar las cautelas, de forma que ninguno de sus miembros habría de aparecer en un programa de televisión hasta después de dictada la sentencia.

g) La retransmisión en directo de un juicio debe respetar los derechos y garantías procesales de las partes. Y hasta que no se apruebe la oportuna normativa, se debería optar por un tratamiento de la imagen que no confunda o manipule al espectador, predisponiéndolo a favor o en contra del acusado. Asimismo, los comentaristas tendrían que limitarse a intervenir antes del comienzo y después de terminada la sesión.

Queden aquí estas recomendaciones como testimonio de un conflicto profundo entre las reglas de funcionamiento de la justicia y la libertad de información que, a día de hoy, ni nuestro legislador ni nuestra jurisprudencia han sabido resolver adecuadamente. Pero sin negar las bondades y posibilidades de la vía del autocontrol ético, sería conveniente aprobar una regulación precisa y cuidadosa que concilie el ejercicio de la libertad de información con otros derechos, bienes y valores constitucionalmente protegidos y, en su defecto, la promoción de criterios jurisprudenciales que hagan posible el entendimiento. $\mathrm{Y}$ es que no parece razonable encomendar en exclusiva la protección de intereses de relevancia constitucional a normas internas y a órganos corporativos. Nótese que, en virtud de lo dispuesto en el artículo 9.2 CE, "corresponde a los poderes públicos promover las condiciones para que la libertad e igualdad del individuo y de los grupos en que se integra sean reales y efectivas", así como "remover los obstáculos que impidan 
o dificulten su plenitud". Y en esta tarea, alguna enseñanza podría extraerse del derecho comparado.

(Recibido el 28-6-2000, aceptado el 15-7-2000) 